\section{ARABENOIC ACID, A NATURAL PRODUCT HERBICIDE OF FUNGAL ORIGIN}

Notes

\author{
Barbara G. IsaAc, Stephen W. Ayer ${ }^{\dagger}$ \\ and RiChARD J. STONARD \\ Monsanto Agricultural Company, \\ A Unit of Monsanto Company, \\ 700 Chesterfield Village Parkway, Chesterfield, \\ Missouri 63198, U.S.A.
}

(Received for publication March 28, 1991)

In the course of screening for herbicides produced by microorganisms, we have isolated an $\alpha, \beta$-unsaturated pentenoic acid, arabenoic acid (1), which inhibits the growth of Arabidopsis thaliana, from the cultured broth of the unclassified fungus F6286. ${ }^{1)}$ This report describes the production, isolation, physico-chemical properties, structure, and herbicidal activity of this novel natural product.

The fungal strain F6286 was isolated from a soil sample collected at LaRue Swamp, Illinois, U.S.A. Two 250-ml Erlenmeyer flasks each containing $50 \mathrm{ml}$ of medium consisting of CZAPEK-Dox $3.5 \%$ and yeast extract $0.2 \%$ were inoculated and fermented at $30^{\circ} \mathrm{C}$ for 3 days on a rotary shaker at $250 \mathrm{rpm}$. Fifty $\mathrm{ml}$ of this inoculum broth was transferred to each of two 2-liter Erlenmeyer flasks containing $500 \mathrm{ml}$ of production medium consisting of cornstarch $1.0 \%$, glucose $0.25 \%$, baker's yeast $0.5 \%$, soybean flour $0.25 \%, \quad \mathrm{KH}_{2} \mathrm{PO}_{4} \quad 0.05 \%$, and Amberlite XAD-7 2\% (pH 6.5). The fermentation was carried out on a rotary shaker at $30^{\circ} \mathrm{C}$ and $250 \mathrm{rpm}$ for 7 days. The herbicidal activity of the resulting broth was assayed by an agar diffusion method using $A$. thaliana as the test organism.

The herbicidal metabolite produced by F 6286 was extracted from $700 \mathrm{ml}$ of sterile culture filtrate by adsorption onto $10 \mathrm{~g}$ of neutral decolorizing carbon. Subsequent elution with acetone gave $0.28 \mathrm{~g}$ of crude, active material which was further purified by RP C18 flash chromatography using a stepwise gradient of $\mathrm{pH} 3$ water (acidified with conc $\mathrm{HCl}$ ) and methanol mixtures. The $3: 1 \mathrm{pH} 3$ watermethanol eluate containing the majority of the herbicidal activity was evaporated under reduced pressure to give $0.12 \mathrm{~g}$ of crude arabenoic acid. This material was further purified by Sephadex LH-20 chromatography with water - methanol $(3: 1)$ elution to yield $0.064 \mathrm{~g}$ of pure arabenoic acid.

Arabenoic acid is readily soluble in water, methanol, and acetone. The molecular formula was established as $\mathrm{C}_{6} \mathrm{H}_{10} \mathrm{O}_{4}$ by HRFAB-MS $((\mathrm{M}-\mathrm{H})$ $m / z$ 145.0501, Calcd: 145.0501). The UV spectrum of 1 in water showed an absorption maximum at $\lambda_{\text {max }}$ nm 230 ( $\varepsilon 38,832)$, consistent with the presence of an $\alpha, \beta$-unsaturated acid bearing one polar substituent. In addition, the IR spectrum (neat) displayed bands at 3200 (br), 1540 and $1401 \mathrm{~cm}^{-1}$ indicative of a carboxylate salt, and at 1640 and $848 \mathrm{~cm}^{-1}$ indicative of a trisubstituted double bond. The existence of this structural feature, accounting for all of the unsaturation in the molecule, was further confirmed by the observation of a one proton singlet at $\delta 5.08$ in the $300 \mathrm{MHz}{ }^{1} \mathrm{H}$ NMR spectrum of 1 in $\mathrm{D}_{2} \mathrm{O}$. Two deshieided methylene groups were observed at $\delta 3.65(2 \mathrm{H}, \mathrm{t}, J=6.3 \mathrm{~Hz})$ and $\delta 2.78(2 \mathrm{H}$, $\mathrm{t}, J=6.3 \mathrm{~Hz}$ ) and the presence of a methoxy group was suggested by a three proton singlet at $\delta 3.50$, thus accounting for all of the carbon atoms of compound 1. The two unobserved protons were attributed to carboxylic acid and hydroxy groups. All six carbons were observed in the $75 \mathrm{MHz}{ }^{13} \mathrm{C}$ NMR spectrum of 1 in $\mathrm{D}_{2} \mathrm{O}(\delta 179.07,169.16$, $100.61,62.10,57.36$, and 36.21).

The ${ }^{13} \mathrm{C}$ chemical shift of the quaternary olefinic carbon $(\delta 169.16)$ indicated that this atom was bonded directly to a methoxy or hydroxy group and was in the $\beta$ position of the $\alpha, \beta$-unsaturated acid moiety. Signals observed in the ${ }^{1} \mathrm{H}$ and ${ }^{13} \mathrm{C}$ NMR spectra at $\delta 5.08$ and $\delta 100.61$, respectively, were consistent with the assignment of the $\alpha$-carbon bearing the lone olefinic proton. The coupled ${ }^{1} \mathrm{H}$ NMR signals observed at $\delta 3.65$ and $\delta 2.78$ were indicative of a $\mathrm{CH}_{2} \mathrm{CH}_{2} \mathrm{OCH}_{3}$ or $\mathrm{CH}_{2} \mathrm{CH}_{2} \mathrm{OH}$ unit which must in turn be attached to the $\beta$-carbon of the double bond.

The remaining unresolved structural features of this molecule included the location of the methyl group and the geometry of the double bond. Utilizing NOE difference spectroscopy, a $40 \%$

$\uparrow$ Present address: National Research Council, Institute for Marine Biosciences, Halifax, Nova Scotia, Canada B3H3Z1. 
enhancement was observed in the intensity of the olefinic proton resonance upon saturation of the methyl resonance. Consequently, the methoxy group must be placed on the double bond, cis to the olefinic proton. Thus, the structure of arabenoic acid was determined to be $(E)$-5-hydroxy-3-methoxy-2-pentenoic acid (1). An agar-based titration assay employing $A$. thaliana showed that treatment with 1 resulted in growth reduction at $50 \mu \mathrm{g} / \mathrm{ml}$, while higher rates resulted in complete inhibition of germination. When evaluated in post-emergence tests, arabenoic acid was active against velvetleaf, morning glory, cocklebur, and Indian mustard at $11.2 \mathrm{~kg} / \mathrm{ha}$.

Confirmation of the derived structure was provided by diazomethane derivatization. Under acidic conditions, arabenoic acid reacted with diazomethane to form the known Penicillium italicum mycotoxin, 5,6-dihydro-4-methoxy- $2 H$-pyran-2-one (2), as identified by comparison of spectral data. ${ }^{2)}$ The lactone 2 was inactive against $A$. thaliana at $50 \mu \mathrm{g} / \mathrm{ml}$.

The existence of the cyclic analog of arabenoic acid as a known natural product raised the question as to whether the free acid was a natural product or an artifact of the isolation procedure. The purification step most likely to cause ring opening was the $\mathrm{pH} 3$ water-methanol RP C18 flash chromatography. In order to evaluate the stability of the lactone under these conditions, the diazomethane reaction product was dissolved in $\mathrm{pH} 3$ water-methanol $(3: 1)$ for 2 hours. The ${ }^{1} \mathrm{H}$ NMR

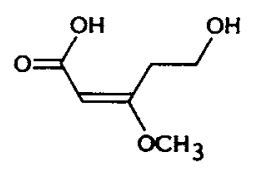

1

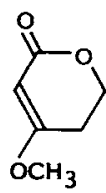

2 spectrum of the resulting neutralized sample contained signals for the lactone only. Arabenoic acid could not be detected in this experiment. A later isolation of arabenoic acid from a separate fermentation of F6286 employed an alternative purification procedure (carbon, RP C18 (neutral water elution), Sephadex LH-20). Only compound 1 was obtained from this procedure thereby confirming that arabenoic acid was not an isolation artifact.

As part of an ongoing program to discover natural product herbicides from microorganisms, the novel pentenoic acid derivative, arabenoic acid (1), was identified as the herbicidal component produced by the unclassified fungus F6286. Although the relatively weak post-emergence whole plant activity exhibited by arabenoic acid precludes synthetic follow-up, the isolation of this compound from a fungal source nevertheless provides further demonstration of the value of microorganisms as a source of novel structures with agriculturally relevant activities.

\section{Acknowledgment}

The authors would like to acknowledge the contributions made to this work by M. Miller-Wideman, K. Crosby, D. Krupa, N. Biest, T. Tran, B. Reich, and $\mathrm{H}$. FuJIWARA.

\section{References}

1) Ayer, S. W.; B. G. IsAac, D. M. Krupa, K. E. Crosby, L. J. Letendre \& R. J. Stonard: Herbicidal compounds from micro-organisms. Pestic. Sci. 27 : $221 \sim 223,1989$

2) Gorst-Allman, C. P.; C. M. T. P. Maes, P. S. Steyn \& C. J. RABIE: 5,6-Dihydro-4-methoxy-2 $H$-pyran-2one, a new mycotoxin from Penicillium italicum. S. Afr. J. Chem. 35: 102 103, 1983 